
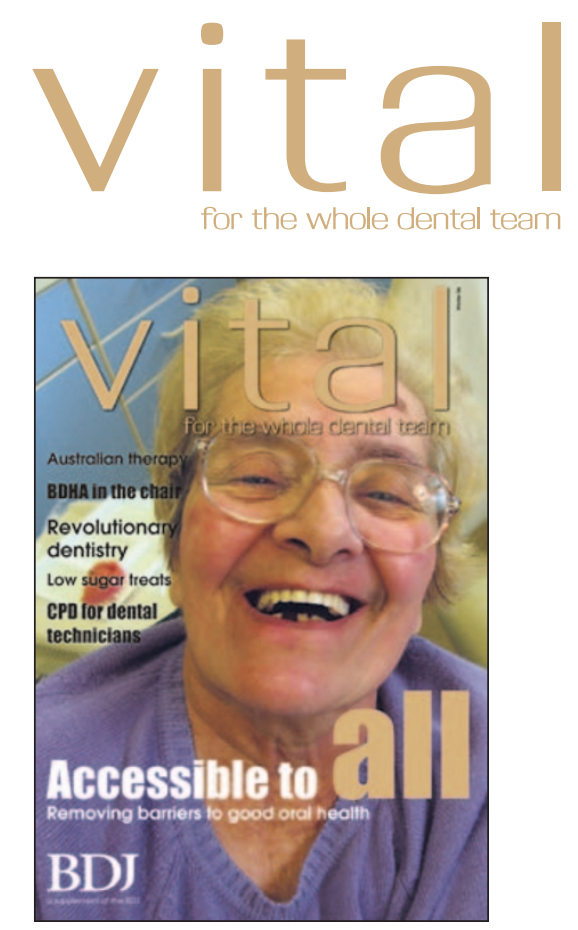

Many thanks to Debbie Lewis for her kind loan of the cover image for this issue, and to our enthusiastic cover girl.

Editor-in-Chief: Stephen Hancocks OBE Editor: Kate Maynard

Art Editor: Melissa Cassem

Production Editor: Esther McKeown

Staff writers: Rowena Milan, Arveen Bajaj

Publishing Manager: Kim Black-Totham

Head of Advertising: Alison Tant

Advertising enquiries: +44 (0)20 78434729

Production Controller: Ian Pope

Vital Editorial Board: Julia Brewin, Michelle Brindley, Larry Browne, Claire Crocker, Ruth Glover, Gordon Watkins, Margaret Wilson

British Dental Journal

The Macmillan Building

4-6 Crinan Street

London N1 9XW

Tel: $+44(0) 2078433678$

Fax: + $44(0) 2078434725$

(c) British Dental Journal 2006. All rights reserved. No part of this publication may be reproduced, stored in a retrieval system or transmitted in any form or by any means, electronic, mechanical, photocopying recording or otherwise, without the prior permission of the British Dental Journal.

The opinions expressed in this publication are those of the authors and not necessarily those of the British Dental Association or the editor. Appearance of an advertisement does not indicate BDA approval of the product or service.

Turn to page 50 to subscribe to receive future issues

\title{
Caring at Christmas
}

How encouraging to discover that $96 \%$ of the people who have completed the readership questionnaire in our autumn issue find Vital useful to them as dental care professionals. I look forward to communicating the complete results to you in 2007; rest assured that we will take your opinions into consideration when planning future issues - and that the 30 of you who would like to be interviewed for a Vital article will not be forgotten!

Meeting some of you face to face on the BDA stand at this year's Dental Showcase was also a big help to me and my colleagues. Thank you to everyone who took the time to share their thoughts with us.

With winter looming, it's as good a time as any

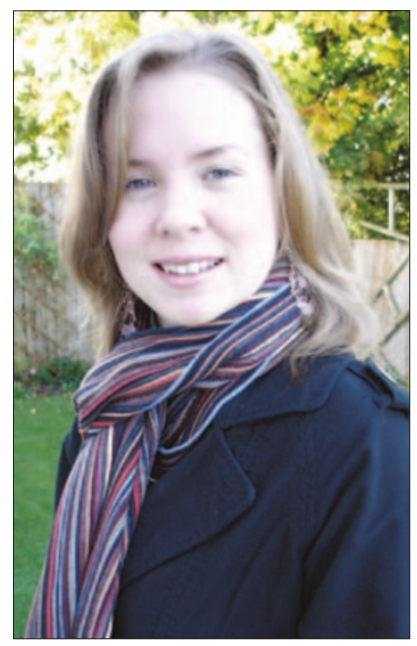
to consider people who might be a little more isolated than others. Finding and registering with a dentist in the first place is the chief concern for a lot of people in the UK, but actually travelling to a dental practice, communicating with staff and moving around the practice are some of the issues that might weigh on the mind of special care patients. Is your dental practice accessible to all? Turn to page 39 to read our cover story.

Imagine living in such a remote region that not only is there no dental care available, but you haven't even heard of a toothbrush. Educating and treating people in these conditions is a regular challenge for roving dental therapist Debbie Beldham (see page 30).

We also turn our focus on dental technicians in this issue, with comprehensive registration information on page 18 and a revealing article on CPD on page 33 . Arveen Bajaj spoke to new BDHA president Mike Wheeler to find out what the future holds in store for dental hygienists (page 28), and restorative dentistry specialist Chris Lynch explains prime, etch and bonding systems (page 21).

To keep you active in case you've gone into hibernation mode, turn to our On your feet section (pages 43-46). You may want make a New Year's resolution to start a new hobby like photography or fell-walking - or if that sounds like too much hard work, you can always get busy in the kitchen. If you have your own tried and tested low or no-sugar recipe, I'd been keen to hear it.

See below for a sneak preview of 2007. In the meantime, from all of us here at Vital, we wish you a happy and fulfilling festive season.

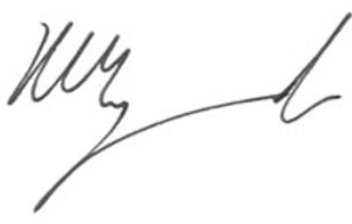

Kate Maynard, Editor

k.maynard@nature.com
VITAL 2007

GUIDE TO PRACTICE MANAGEMENT

STRESS AS A POSITIVE MOTIVATOR

CLINICAL GOVERNANCE FROM A DCP VIEWPOINT DESIGNER RECEPTIONS 